\title{
3q27.3 microdeletion syndrome
}

INSERM

\section{Source}

INSERM. (1999). Orphanet: an online rare disease and orphan drug data base. 3927.3 microdeletion syndrome. ORPHA:397695

3q27.3 microdeletion syndrome is a rare chromosomal anomaly syndrome, resulting from the partial deletion of the long arm of chromosome 3, characterized by mild to severe intellectual disability, neuropsychiatric disorders of the psychotic and dysthymic spectrum, mild distinctive facial dysmorphism (incl. slender face, deep-set eyes, high nasal bridge with a hooked nose, small, low- set ears, short philtrum, small mouth with thin upper lip, prognathism) and a marfanoid habitus. 